\title{
DOMESTIC ACQUISITIONS, INSTITUTIONAL HETEROGENEITY AND THE INTERNATIONALIZATION OF CHINESE FIRMS
}

\author{
YULIA MURATOVA \\ Department of Management \\ Aarhus University \\ Aarhus 8210, Denmark
}

\section{INTRODUCTION}

Liability of foreignness (LOF), resulting from the institutional distance between home and host countries, increases the risk of doing business abroad, thereby deterring firms from internationalization. Chinese firms particularly suffer from LOF because of the distinctively different home institutional environment and Sinophobia (Deng, 2013). Yet, the internationalization pattern of Chinese firms evidences that they take significant risks investing in more distant countries (Lyles, Li, \& Yan, 2014). To shed light on this puzzle, I suggest that institutional heterogeneity in China offers firms an opportunity to learn how to overcome LOF if they have acquisition experience outside of the headquarters' home province.

I probe into the institutional heterogeneity further and discuss the implications of the coastal-inland institutional divide in China for building counter-LOF routines. I suggest that coastal and inland acquisition experiences result in firms crafting different kinds of routines. Moreover, routines developed by inland firms through coastal acquisition experience may be more valuable for internationalization than routines of coastal firms developed through acquisition growth in inland provinces. I test these ideas on a sample of manufacturing firms listed in China tracing their domestic and cross-border acquisition activities from 2006 to 2015.

The study makes several contributions to the literature on the internationalization of Chinese firms. First, I develop novel measures of domestic acquisition experience that are Chinaspecific (Barney \& Zhang, 2009). Second, I show that the study of the effect of institutions on the internationalization of Chinese firms should go beyond their headquarters' institutional environment. Third, while previous studies view institutional heterogeneity of Chinese provinces as a source of transaction costs firms choose to avoid, I show that Chinese firms, particularly inland, may derive value from it by developing counter-LOF routines (Boisot \& Meyer, 2008). Fourth, the findings help to reassess just how risky internationalization of Chinese firms is (Luo \& Tung, 2007).

\section{THEORETICAL BACKGROUND AND HYPOTHESES}

Firm strategy is a function of experience, which is stored in organizational memory as routines (Argote \& Miron-Spektor, 2011). These routines can be invoked in the future to facilitate a firm's decision-making and afford a more effective strategy implementation. Firms usually develop first growth routines through domestic activities, however, their value depreciates in cross-border growth because of the institutional differences requiring the development of counter-LOF routines (Nadolska \& Barkema, 2007).

I argue that institutional heterogeneity of Chinese provinces provides the context in which firms conducting domestic cross-province acquisitions may develop such routines. Local firms conducting cross-province acquisitions can learn how to develop counter-LOF routines 
with respect to unfamiliarity hazards related to the lack of knowledge or experience in a host environment, discrimination hazards stemming from the differential treatment by the host governments, businesses, or consumers, and relational hazards defined as the challenges of managing business relationships at a distance (Eden \& Miller, 2004). Once firms have acquisition experience outside the home province, they become more equipped for international growth. The main hypothesis is as follows:

\section{Hypothesis 1: The likelihood of conducting a cross-border acquisition increases with acquisition experience outside of home province.}

\section{Heterogeneity of Acquisition Experience}

Differences between coastal and inland provinces constitute another spatial dimension of institutional heterogeneity in China. It leads to differences in organizational routines that acquiring firms develop when dealing with discriminatory and relational hazards. Therefore, firms with acquisitions in inland and coastal provinces go through different experiences and thus develop different kinds routines. According to the organizational learning theory, heterogeneity of experience is a foundation of superior routines (Zahra \& George, 2002), which, I argue, can be achieved only if inland firms venture into coastal provinces and vice versa. Hence:

Hypothesis 2a: The likelihood of conducting a cross-border acquisition by inland firms will be greater when they have coastal acquisition experience than when they have inland acquisition experience.

Hypothesis 2b: The likelihood of conducting a cross-border acquisition by coastal firms will be greater when they have inland acquisition experience than when they have coastal acquisition experience.

Coastal and inland firms reduce organizational rigidity through acquisition experience outside their home province region. However, coastal firms may already possess congenital knowledge about how to operate in an opaque state-led environment. This means that while for inland firms acquisition experience in coastal provinces helps broaden their routine portfolio, coastal firms with experience in inland provinces may only deepen their routines.

Hypothesis 3: Inland firms with coastal acquisition experience have a higher likelihood to acquire cross-border than coastal firms with inland acquisition experience.

\section{METHOD}

The analysis is based on a sample of manufacturing firms listed on the Shanghai and Shenzhen Stock Exchanges between 2006 and 2015 with Chinese ultimate ownership. For acquisition data I used Zephyr produced by Bureau van Dijk. The sample contains 10,440 firmyear observations.

Cross-border acquisition is ' 1 ' if a firm completed an acquisition in the given year and ' 0 ' if not. Acquisition experience outside of home province was measured as the number of provinces entered by a firm through an acquisition mode per year. Beijing, Tianjin, Shanghai, 
Jiangsu, Zhejiang, Shandong, Guangdong, Hebei, Liaoning were classified as coastal provinces, while all the rest were classified as inland. I further divided acquisition experience outside of home province into the coastal and inland acquisition experiences. The coastal/inland acquisition experience is the number of new coastal/inland provinces entered through an acquisition mode per year.

I controlled for several variables which could impact the likelihood of a firm's internationalization: firm export intensity, joint venture experience with a foreign firm, the number of foreign and domestic subsidiaries, percentage of state ownership, performance, R\&D intensity, firm age and size, the level of diversification, market size of the province. Industry and year dummies were also included.

To account for the dichotomous nature of the dependent variable and focusing on the effect of the time-invariant independent variable, I estimated binary logistic regression with random effects. Out of 199 acquisitions, 79 were conducted by serial acquirers. To address possible autocorrelation, I included a one-year lagged depended variable on the right-hand side of all statistical models.

\section{RESULTS}

The results show a positive and significant impact of acquisition experience outside of home province on a subsequent cross-border acquisition, lending support to Hypothesis 1.

The interaction effects of firm HQ location and coastal/inland acquisition experience on the likelihood of a firm internationalization are both significant. The results specifically show that entering a new coastal province improves the chance of an inland firm to acquire crossborder more than entering other inland provinces. Likewise, entering an inland province increases the propensity of a coastal firm to acquire cross-border more than entering other coastal provinces.

Upon further examination of marginal effects, I found a statistically significant positive effect of inland firms' coastal acquisition experience on the likelihood of acquiring cross-border. The marginal effect of coastal firms' inland acquisition experience on cross-border growth is not significant. This provides support for Hypothesis $2 \mathrm{a}$ and 3, but not to Hypothesis $2 \mathrm{~b}$.

\section{DISCUSSION}

The premise of the study is that internationalization is risky and one specific risk is caused by LOF. I argued that institutional heterogeneity in China makes it possible for firms to develop counter-LOF routines through domestic acquisition experience. The results showed that acquisition experience outside of home province is a strong predictor of cross-border growth. I further found that while firms from inland provinces with coastal acquisition experience are more likely to internationalize than with inland acquisition experience, coastal firms do not seem to develop their counter-LOF routines through cross-province acquisition growth.

Together, these findings offer novel insights into the scope of the domestic institutional context that shapes the internationalization of Chinese firms (e.g. Lu et al. 2014). The study also contributes to the discussion of the effect of institutional heterogeneity of Chinese provinces on firm strategy. Prior studies have argued that domestic institutional heterogeneity entails large transaction costs of crossing provincial borders, therefore making Chinese firms "escape" into foreign countries (Boisot \& Meyer, 2008). This study indicates that transaction costs involved in 
moving across provinces are precisely what enables organizational learning about how to overcome LOF in cross-border growth. Finally, the study provides evidence that Chinese firms learn how to overcome LOF by expanding domestically. Hence, future studies should consider that the learning curve of Chinese firms starts not with their first cross-border entry, but with domestic growth.

\section{CONCLUSION}

I investigate the effect of domestic acquisition experience of Chinese firms on subsequent cross-border acquisitions, arguing that institutional heterogeneity of Chinese provinces offers firms an opportunity to develop counter-LOF routines. I also suggest that coastal and inland firms develop different routines from coastal and inland acquisition experience. I test the hypotheses on a sample of Chinese listed firms observing their acquisition behavior between 2006 and 2015. The findings contribute to the literature on the internationalization of Chinese firms and China-specific management theories.

\section{REFERENCES AVAILABLE FROM THE AUTHORS}

